\title{
STUDY OF ION IMPLANTATION INTO GAN SUBTRATE AND THIN FILM BY METAL ORGANIC CHEMICAL VAPOR DEPOSITION TECHNIQUE (MOCVD)
}

\author{
Waseem Ullah Shah ${ }^{1}$, Mohib Ullah Khan ${ }^{2}$, Zarin Ullah ${ }^{3}$, Shahzeb Burki ${ }^{4}$, Dil Faraz Khan ${ }^{5}$ \\ E-Mail Id: mohaibarain123@gmail.com, waseemullahshah303@gmail.com \\ Department of Physics University of Science \& Technology Bannu, Bannu-28100, Kp Pakistan
}

\begin{abstract}
In this theoretical and experimental research paper, the study of ion implantation into GaN is studied. The $\mathrm{GaN}$ structure is studied and the GaN thin film is made on sapphire (silicon carbide) substrate through metal organic chemical vapor deposition (MOCVD) process. The ion implantation technique is also studied well in this paper, the damages, dislocations and defects produced due to ion implantation, the microstructure analysis of GaN crystal is discussed and application of ion implantation is also given here.
\end{abstract}

Keywords: GaN, Thin Film, Metal Organic Chemical Vapor Deposition, Ion Implantation.

\section{INTRODUCTION}

Semiconductors may be elemental materials such as silicon and germanium or compound semiconductors such as gallium arsenide and indium phosphate or alloys such as silicon germanium or aluminum arsenide [1].the III-V nitrides are basically heterostructure and are having outstanding current interest of devices including blue and ultraviolet (UV) light emitting diodes and lasers, high temperature/high power electronics, visible-blind ultraviolet photo detectors and field-emitters structures [2].among III-V nitrides, the gallium nitride ( $\mathrm{GaN})$ is basically versatile nature material because of its electrical and optical properties like large direct band gape $(3.4 \mathrm{eV})$, extremely having high hardness, very large heterojunctions offset, high thermal conductivity and high milting point temperature. these properties make GaN ideally suitable for blue-UV LED,s laser diodes(LD,s) and a wide range of other electronic and optoelectronic materials applications.[3].during past few years, it is seen high level of commercial and scientific interest in wurtzite GaN semiconducting materials, and considerable efforts have been devoted for improvement of quality film depositing for devices[4].GaN is very hard, mechanically stable material with large heat capacity, in pure from it resist creaking and can be deposited in thin film on sapphire or silicon carbide, GaN crystal is basically rich defects operations ranging from 100 million to 10 billion per $\mathrm{cm}^{2}$.the interesting capabilities of III-V nitrides has led very much improvement in the epitaxial film growth techniques ,such as metal organic chemical vapor deposition (MOCVD), and molecular beam epitoxy (MBE), and hydride vapor phase epitoxy(HVPE).among these techniques, MOCVD is the most popular toll and technique owing to its strong background in industrial application, however due to higher thermal stability of the $\mathrm{N}-\mathrm{H}$ bond in ammonia(NH3) molecule, which serves as the $\mathrm{N}$ source for the MOCVD growth of GaN film applicably, high temperature based MOCVD growth is basically necessary for epitaxial films growth[5]. GaN when doped with silicon make $\mathrm{N}$-type materials and with magnesium to P-type materials [6].SI and $\mathrm{Mg}$ atoms doped in such a way that they change the direction of the GaN crystal growing, and introducing tensile stresses phenomenon and making them brittle and more hard [8].the discovery of P-type material is still in deficiency, and we have to discuss it in this paper by considering low temperature growth on buffer thin film. When $\mathrm{GaN}$ is doped with suitable and effective transition metal just manganese, nanotubes of $\mathrm{GaN}$ are proposed and realized for the actual applications in Nano scale electronics, optoelectronics and biochemical-sensing applications of devices making [7].

\subsection{GaN CRYSTAL STRUCTURE}

Usually $\mathrm{GaN}$ is crystallize in different lattice formation ways just as wurtzite, zinkblende, rock-salt, as under stable condition growth in thermodynamical equilibrium state, GaN and its alloy just as ALGaN chain form thermally stable hexagonal wurtzite structure, but as concern with another two structures zinkblende and rock-salt are metastable state, which means that the structure is not in minimum energy state and non equilibrium state. As concerns with wurtzite structure it has a hexagonal unit cells and consisting of two sub lattices structures: as one lattice is of gallium atoms and other lattice is of nitrogen atoms. So that these two sub lattice is of gallium atoms and the other lattice is of nitrogen atoms. So that these two sub lattices are combining together to form the wurtzite structure. The offset of the two lattices is $5 / 8 \mathrm{c}$ as shown in fig 1.1. The chemical bonding of III-nitrides crystals such as $\mathrm{GaN}$ is predominantly stable covalent, which means that atom is bonded tetrahedrally with four atoms of other nature. The large electro-negativity between $\mathrm{Ga}$ and $\mathrm{N}$ are determining the stability of structure phase of element. Wurtzite lattice is having hexagonal unit cell with a basis of four atoms collaboratively, two of each kind.

DOI Number: https://doi.org/10.30780/IJTRS.V05.I03.003

pg. 16

Www.ijtrs.com

www.ijtrs.org

Paper Id: IJTRS-V5-I1-004

Volume V Issue III, March 2020 

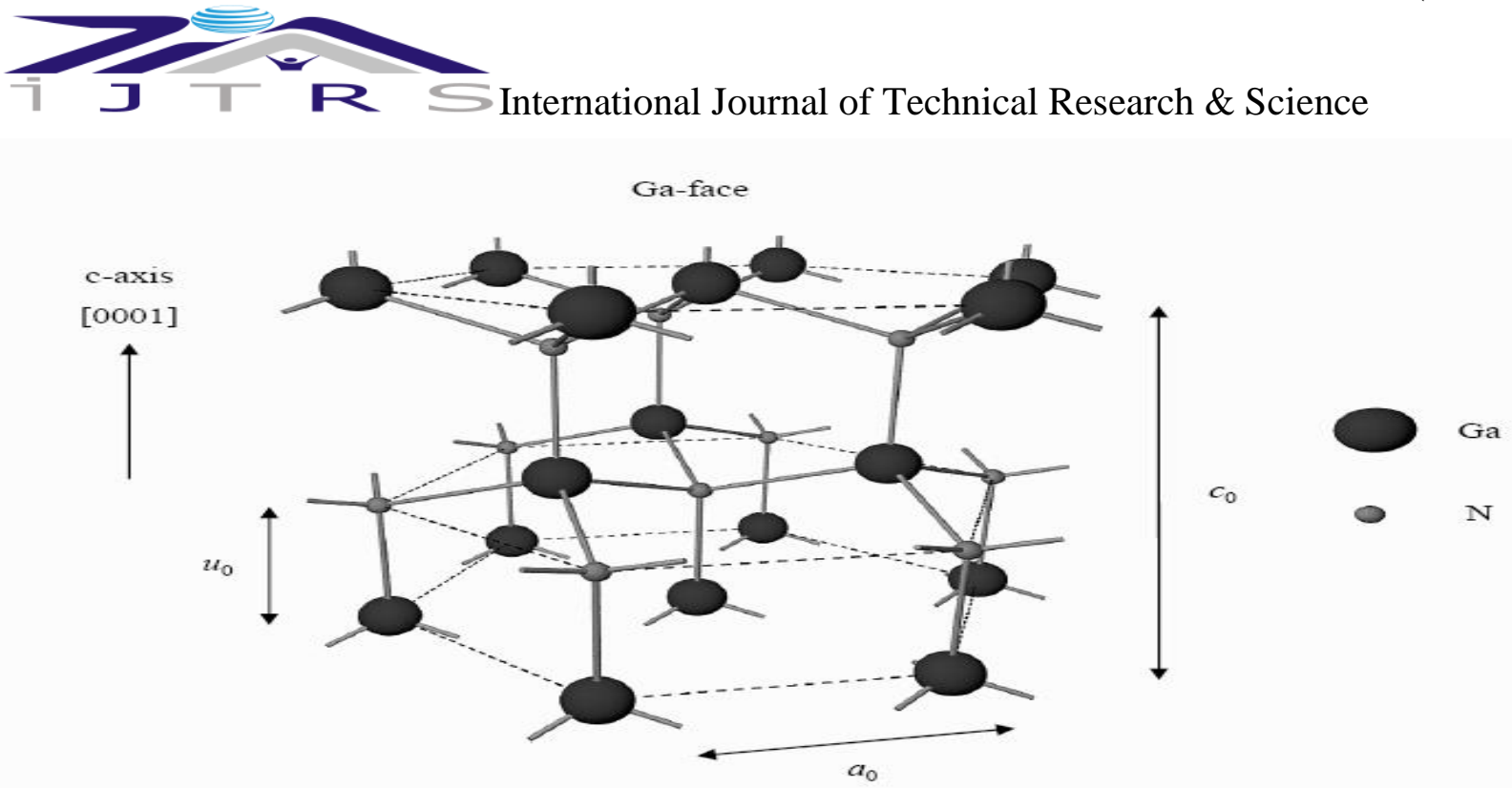

Fig. 1.1 Atomic Arrangement in Ga-face GaN Crystals

There is no inversion symmetry in these lattices along the (0001) direction or c-axis, which is obeying the conventional direction showing by vector pointing from a $\mathrm{Ga}$ atom to the nearest neighbor $\mathrm{N}$ atom as a pointing vector tip. But because of lack in inversion symmetry all atoms are seen same on each side of the bonds of same plane. Which is corresponding to the symmetrically (0001) and ( $000 \overline{1})$ crystalline faces. Now by flipping the Gaface material upside down we can obtained for $\mathrm{N}$-face material easily.[8].the most common growth direction of hexagonal GaN is normal to the $\{0001\}$ basal plane, where the atoms are arranged in bilayers of two closely spaced hexagonal layers, one with cations and other with anions, so that the bilayers have a polar faces, in case of GaN the basal surface should be either Ga or N-faced, in Ga-faces we means gallium on top of $\{0001\}$ bilayers lattice, which corresponds to $\{0001\}$ polarity of $(\mathrm{Ga})$.
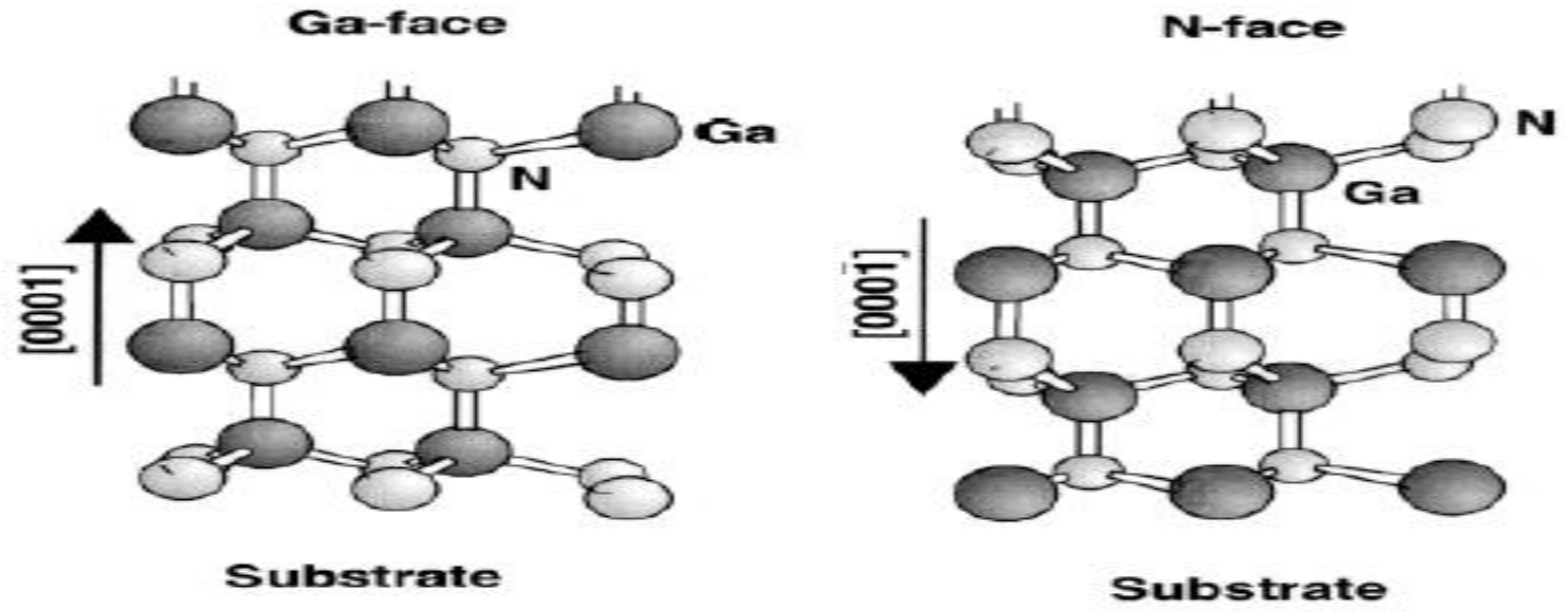

Fig.1.2. Crystal Structures showing Ga-face and N-face of GaN Wurtzite

It is also been reported here that high-quality epitaxial growth of GaN film that is deposited by MOCVD tool on cplane side sapphire substrate and grown in the (0001) direction respectably with Ga-faced surfaces, but in negative side of the lattice position used MBE growth at ( $000 \overline{1})$ [9].

\subsection{Band Structure of Wurtzite GaN}

Band structure of wurtzite $\mathrm{GaN}$ is shown here, minimum portion of the conduction $(\mathrm{CB})$ band lies directly above the maxima of the valence band (VB) [10].due to phenomenon of spin-orbital interaction the valence band is splitted into three sub bands as fermions looking and from crystal symmetry it can be traced easily. For wurtzite the activation energy of the atoms as acceptors is $E_{A}$. but the energy which shows separation between $M$ and $L$ valleys state are $\left(\mathrm{E}_{\mathrm{M}-\mathrm{L}}\right)$ energy for spin-orbital splitting is $\left(\mathrm{E}_{\mathrm{so}}\right)$ and energy for crystal-field splitting is $\left(\mathrm{E}_{\mathrm{cr}}\right)$ and having acceptable periodic values of $4.7-5.5 \mathrm{ev}, 4.5-5.3 \mathrm{ev}, 0.008 \mathrm{ev}$ and $0.04 \mathrm{ev}$ respectively as shown in fig. 1.3. 


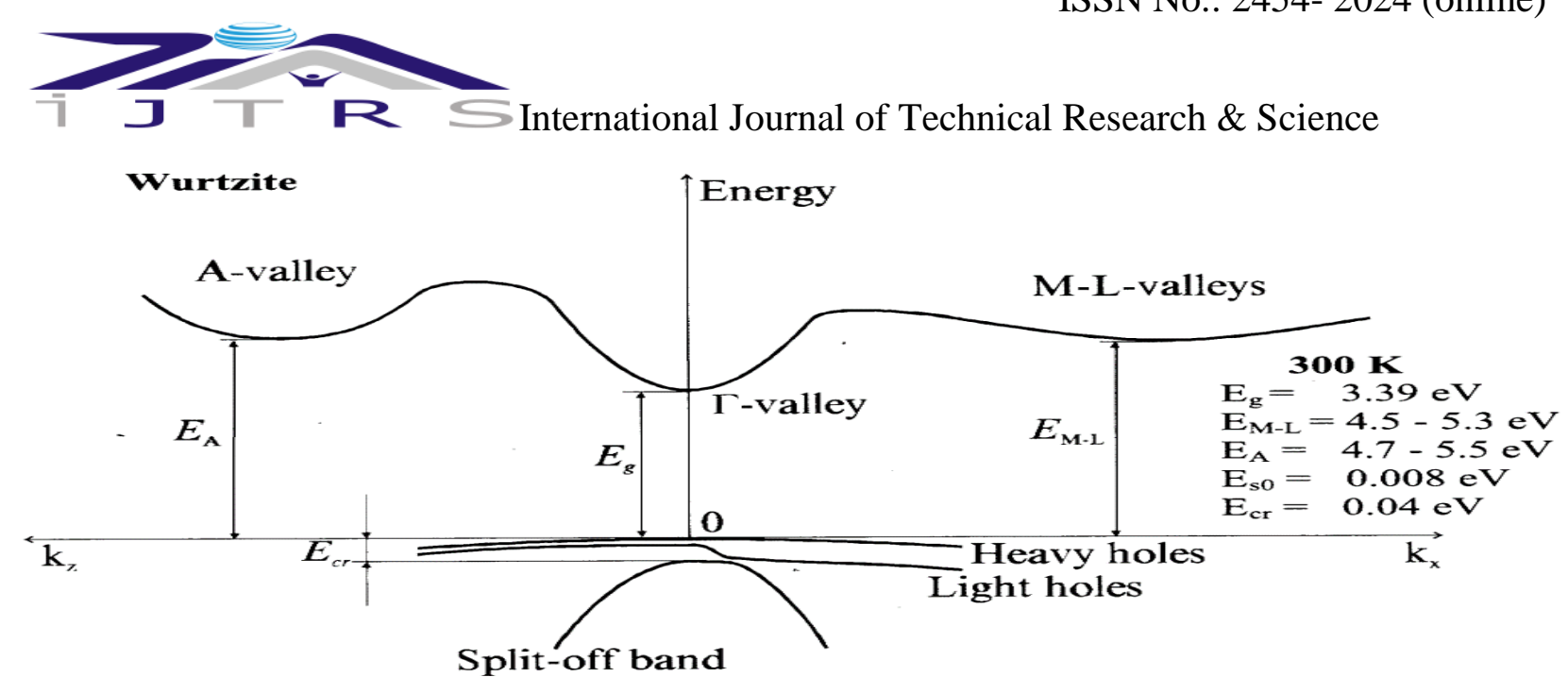

Fig.1.3 Band structure of Wurtzite GaN

Table-1.1 Some Important Properties of Wurtzite GaN [11, 12]

\begin{tabular}{|l|l|}
\hline Molecular formula & $\mathrm{GaN}$ \\
\hline Molar mass & $83.7297 \mathrm{~g} / \mathrm{mol}$ \\
\hline Appearance & Yellow powder \\
\hline Density & $6.15 \mathrm{~g} / \mathrm{cm} 3$ \\
\hline Melting point & $>2500 \mathrm{oc}$ \\
\hline Energy band gap Eg $(300 \mathrm{~K})$ & $3.42 \mathrm{eV}$ \\
\hline Heat of sublimation & $72.4 \mathrm{kcal} / \mathrm{mol}$ \\
\hline Thermal expansion coefficient & $5.59 \times 10^{-6} / \mathrm{k}$ \\
\hline Thermal conductivity $(\mathrm{k})$ & $1.3 \mathrm{~W} / \mathrm{cm} . \mathrm{k}$ \\
\hline Debye temperature $\Phi_{\mathrm{D}}($ at $0 \mathrm{k})$ & $600 \mathrm{k}$ \\
\hline Refractive index $\mathrm{n}(1 \mathrm{ev})$ & 2.35 \\
\hline Dielectric constant $\varepsilon_{\mathrm{r}}$ & 10.4 \\
\hline High frequency dielectric const $\varepsilon_{\infty}$ & 5.47 \\
\hline Electron effective mass, $\mathrm{m}_{\mathrm{e}}$ & $0.22 \mathrm{~m}_{\mathrm{o}}$ \\
\hline Hole effective mass, $\mathrm{m}_{\mathrm{p}}$ & $>0.8 \mathrm{~m}_{\mathrm{o}}$ \\
\hline
\end{tabular}

Table.1.2. The Lattice Parameters of the Wurtzite GaN at 300K

\begin{tabular}{|l|l|}
\hline Parameters & GaN \\
\hline $\mathrm{a}_{\mathrm{o}}\left(\mathrm{A}^{\mathrm{o}}\right)$ & 3.189 \\
\hline $\mathrm{c}_{\mathrm{o}}\left(\mathrm{A}^{\mathrm{o}}\right)$ & 5.185 \\
\hline $\mathrm{c}_{\mathrm{o}} / \mathrm{a}_{\mathrm{o}}(\exp )$ & 1.6259 \\
\hline $\mathrm{c}_{\mathrm{o}} / \mathrm{a}_{\mathrm{o}}(\mathrm{cal})$ & 1.6336 \\
\hline Cation-anion bond length ratio $\left(\mathrm{u}_{\mathrm{o}}\right)$ & \\
\hline
\end{tabular}

The controlled n-type conductivity in binary alloy and alloys of $\mathrm{GaN}$ can be regularly achieved in case by the proper doping of Silicon ( $\mathrm{Si}$ ) crystal from the IV group of periodic table in both of the techniques as vacuum deposition and MOCVD growth. The Si substitutes most of the Ga atom in the lattice mode and providing a loosely bounded electron portion. The solubility of $\mathrm{Si}$ in $\mathrm{GaN}$ is high and is of the order of $10^{20} \mathrm{~cm}^{-3}$. Therefore, $\mathrm{Si}$ is most suitable for doping with group-III N elements. And Beside Si, Germanium (Ge) and selenium (Se) are also looked successful while used to obtain n-type $\mathrm{GaN}$ [13]. That is also most important type in $\mathrm{GaN}$ crystal which can be obtained by the doping of Mg crystal from group II of periodic table. Amano et al [14] and Nakamura et al [15] so then we can easily achieved p-type nitrides crystal by using atmospheric MOCVD techniques with in-situ.Mg-doping. Amano et al achieved the initial breakthrough by converting compensated Mg-doped GaN crystal to the material conducting as p-type material by the process of carrying low energy electron beam irradiation partially [16].Xu et al [17] in 2003 successfully prepared at room temperature the $\mathrm{Mn}$-implanted $\mathrm{GaN}$ with ferromagnetism. The structural properties and optical properties of Mn-implanted $\mathrm{GaN}$ films were then investigated. The films, with $\mathrm{Mn}$ implanted in $150 \mathrm{keV}$ 


\section{TR SInternational Journal of Technical Research \& Science}

studied were grown by MOCVD. In the reflectance spectra a new energy band with a minimum at $2.9 \mathrm{ev}$ was observed. With an increase in Mn-doping the yellow band emission typically observed in undoped GaN was found disappeared. Wang et al [18] investigated in 2004 the effect of post implant annealing on the electrical and optical properties of Si-implanted GaN films thickness. Results were obtained from several measurements techniques including micro Raman scattering and hall measurement, room temperature photoluminescence (PL), and high resolution x-ray diffraction (HRXRD) were correlated supposed to study the residual stress ,crystalline quality ,dopants activation and behavior of damage removal,etc. with up to $1100^{\circ} \mathrm{C}$ increasing annealing temperature, basically line width broadening of near band edge emission in the PL spectrum which is in agreement with The carrier concentration that increased monotonically .it was shown that the implantation-induced defects From the systematic measurements, especially at $1100^{\circ} \mathrm{C}$ point defects could not be completely annealed out.. In 2006 Pereira et al [19 from net] at temperatures below $20 \mathrm{~K}$ implanted protons (deuterons) on Gallium nitride single crystals and then studied at $8 \mathrm{~K}$ by infrared absorption spectroscopy without any intermediate heating of the samples. But unfortunately they confused because the spectrum exhibited at $1456 \mathrm{~cm}^{-1}$ an absorption line which was not seen in the spectra recorded on $\mathrm{D}^{+}$implanted samples which shows the disagreement. This concludes that the $1456 \mathrm{~cm}^{-1}$ line represents a vibrational mode of a hydrogen related defect. Another set at 3027 and $3139 \mathrm{~cm}^{-1}$ of lines was revealed. These lines were ascribed to $\mathrm{N}-\mathrm{H}$ stretch modes of Ga vacancy defects which is decorated and designed with hydrogen atoms $\left(\mathrm{V}_{\mathrm{Ga}}-\mathrm{H}\right)$. In 2008 You et al [20 from net] studied ions implantation influence of $\mathrm{C}$, $\mathrm{N}, \mathrm{O}, \mathrm{Mg}, \mathrm{Si}$ and co-implants $(\mathrm{Mg}+\mathrm{Si})$ with fluencies on yellow luminescence (YL) properties in the wide range $10^{13}-10^{17} \mathrm{~cm}^{-2}$ on wurtzite GaN by PL spectroscopy. And by MOCVD grown two types of n-type GaN samples labeled as No-1 and No-2 were studied. They observed a strong YL for their as grown No-1 samples while they getted week YL for No-2 sample recipe. It was found that with increasing $\mathrm{N}, \mathrm{O}, \mathrm{Mg}$, and Si implantation the $\mathrm{I}_{\mathrm{YL}} / \mathrm{I}_{\mathrm{UV}}$ decreases gradually; ranging from $10^{13}$ to $10^{17} \mathrm{~cm}^{-2}$ for No-1 samples after thermal and physical annealing process. This means that non radiative recombination centers can induce by ion implantation and can usually cause reduction of both the near band edge UV transition and YL in GaN. In 2008 Majid et al [21] used X-ray diffraction and Raman scattering techniques to studied micro structural changes in GaN due to neon ion implantation. As observable by Raman measurements the implanted sample having a dose of $10^{14} \mathrm{~cm}^{-2}$ and are not depict lattice deformation process .but for the formation of stable cavities in GaN lattice, Such a low implantation dose for neon is insufficient to do. But with the implantation dose of $2 \times 10^{15} \mathrm{~cm}^{-2}$ and other higher doses were found to increase the size of cavities and concentration as well. In the Raman spectra of GaN A sharp peak at $1122 \mathrm{~cm}^{-1}$ was attributed because due to the plasma line of laser. They recorded, new feature at $1595 \mathrm{~cm}^{-1}$ the intensity of which was increased with increase in dose. Majid et al [22] in 2008 studied the luminescence properties of neon implanted GaN thin films by the basic effect of thermal anneling, for that purpose, on the samples implanted with different doses ranging from $10^{14}$ to $9 \times 10^{15} \mathrm{~cm}^{-2}$ the low temperature PL measurements were carried out and isochronally annealed at $800 \mathrm{C}^{\circ}$ and $900 \mathrm{C}^{\circ}$. A new peak was observed appearing at $3.44 \mathrm{eV}$ in the low temperature PL spectra of all the implanted samples after annealing at $900 \mathrm{C}^{\circ}$. This peak was identified as an oxygen related peak which is obtained during the recombination of the oxygen donor level and a hole in the valence band with electron. Parikh et al. [23 from net] studied, by RBS/C and XTEM, GaN bombarded with $120 \mathrm{keV} \mathrm{Mg}$ and $160 \mathrm{keV} \mathrm{Si} \mathrm{ions} \mathrm{at} 550 \mathrm{C}^{\circ}$.

\section{ION IMPLANTATION TECHNIQUE:}

Ion implantation is basically a surface modification process, in which ions are injected into the near surface region of a solid substrate from some special source. In accelerator High energy ions in the KeV to MeV energy range are produced and then directed as a beam onto the surface of the substrates to create growth and changes. On the substrates with kinetic energies 4 to 5 orders of magnitudes the ions impinge which is greater than the binding energy of solid substrates and with the surface upon impact and form an alloy [24]. Ion implantation has become a highly developed tool for modifying the properties and structure of semiconductors materials [25]. The final implant profile are dose $\left(\right.$ atoms $/ \mathrm{cm}^{2}$ ) and energy in $\mathrm{KeV}$ the two key parameters defining these [26]. Ion implantation is used in semiconductor device fabrication and various applications in materials science research and in metal finishing. In the target the ions introduce both the chemical change that they can be a different element than the target, and a structural change in target and that the crystal structure of the target can be damaged or even destroyed and vanished. Ion implantation equipment consists of ion source and target chamber, accelerator. Ions of the desired element are produced in ion source. The ions are accelerated electro statically to a high energy in accelerator beam. In target chamber, the ions impinge on a target, which is the material to be implanted [27].but basically each ion reaction is typically a single atom, and thus the actual amount of implanted material in the target is Basically the integral sum over the time of the ion current. And thus the dose which can be implanted in a reasonable amount of time is small because the currents supplied by implanters are typically small (microamperes). Thus, particularly ion implantation finds application of reaction in cases where the amount of chemical change required is very small. An energetic ion which penetrates and enters into a solid material and loses its energy via both electronic 


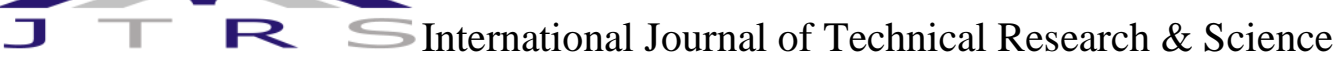

excitation/ionization and do elastic collision with the target atoms before coming to rest in the host lattice as in case of modern physics effects laws [28].

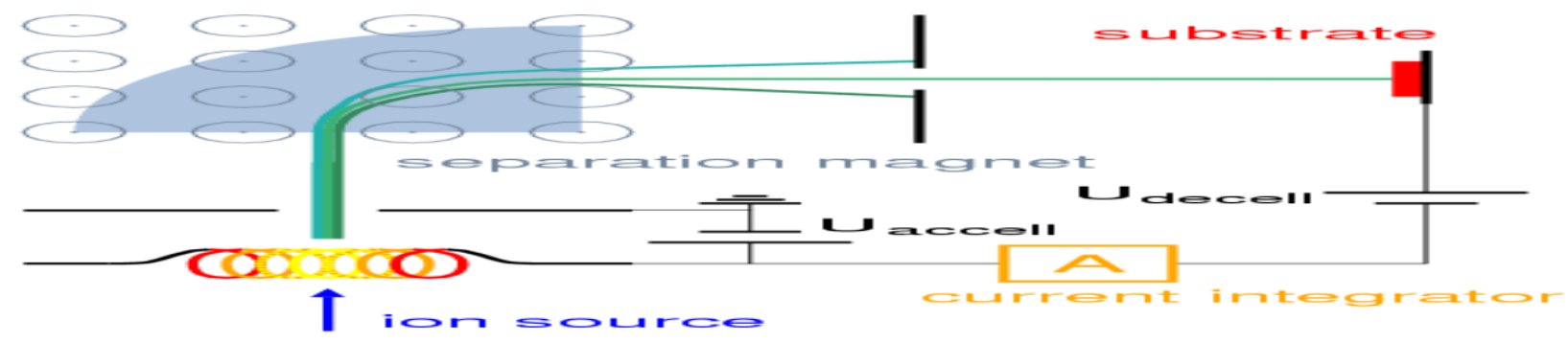

Fig. 2.1 Schematic Diagram of Ion Implantation Technique

\section{RESULT AND DISCUSSION}

Now here we will discuss some important effects which occurs during ion implantation into GaN crystal lattice, following are the main aspects of ion implantation into GaN: (i) damage build-up and amorphization occurring, (ii) preferential surface disordering and loss of nitrogen during ion bombardment, (iii) ion-beam-induced porosity(which liquid or air may pass) of amorphous $\mathrm{GaN}$ due to material dissociation, (iv) anomalous surface erosion during ion bombardment at elevated temperatures, (v) the effect of implantation disorder on mechanical properties, (vi) current progress on annealing of implantation disorder, (vii) electrical and optical doping, and (viii) electrical isolation. Emphasis is given to current problems which may hinder a successful application of ion implantation in the fabrication of $\mathrm{GaN}$-based devices. Lattice disorder is always a natural effect of ion bombardment. Undesirable damage Produced by an ion beam is, in fact, the main problem for satisfactory electrical and optical doping Made by ion implantation because it will make hurdles and complexities during process.
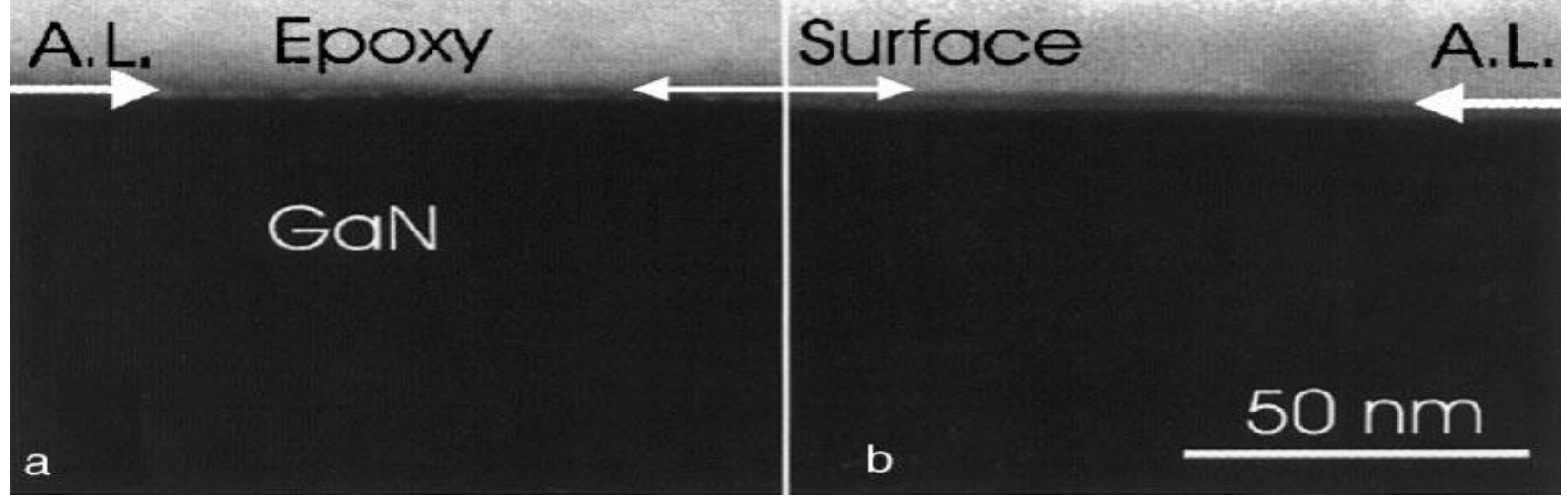

Fig. 3.1 Increase in the RBS Random Yield in the Near-Surface Region with Increasing Ion Dose

Dry etching is also always followed by undesirable damage Introduced into near-surface layers. Therefore, studies of implantation disorder and its consequences are necessary for a successful application of ion implantation in device fabrication. Here, we discuss damage build-up in wurtzite GaN under ion bombardment process. An energetic ion beam penetrating through a GaN crystal and generates a collision cascade which consists of vacancies in the gallium and nitrogen sub lattices ( $\mathrm{VGa}$ and $\mathrm{VN}$ ), gallium and nitrogen interstitials (Gai and Ni) [29], the amorphous zone of cascade in interstitial of place when damage level is of threshold value $8 \pm 10$. The thickness of the layer modified by ion bombardment as well as the number of atomic displacements generated depends on ion mass and energy It is well-known that complex dynamic annealing processes in solids under ion bombardment are highly dependent on implant conditions such as ion mass, energy, dose, substrate temperature, and beam flux .[30]. The first study of damage accumulation in GaN reported by Tan et al. [31] revealed that GaN Exhibits very efficient dynamic annealing during bombardment with $90 \mathrm{keV} \mathrm{Si} \mathrm{ions} \mathrm{at} \mathrm{liquid} \mathrm{Nitrogen} \mathrm{temperature} \mathrm{(LN2).} \mathrm{This} \mathrm{conclusion}$ directly follows from the fact that the amount of lattice has indicated that the loss of $\mathrm{N}$ from the GaN surface during ion bombardment is not the main reason for preferential disordering in the near-surface region of GaN. It has been suggested that the GaN surface acts as a strong sink for migrating point defects. However, for high-dose implantation, when GaN becomes amorphous, N-deficiency is evident even from RBS/C spectra. This has been assumed to reflect the loss of $\mathrm{N}$ from the surface during ion bombardment. Moreover, $\mathrm{N}$ loss has also been observed by Auger electron spectroscopy after plasma-induced etching of the GaN near-surface region [32]. Damage produced in GaN by ion bombardment has been studied by XTEM, Energetically favorable for such planar defects 


\section{T}

to grow rather than to nucleate an amorphous phase for heavy-ion irradiation at RT process. Additional studies are highly desirable to understand the evolution and saturation of defects in GaN during ion bombardment.becouse that defects are somehow special; it cannot be looked precisely by ordinary tools and methods. That needs high power AFM like devices to look defect type fluctuation easily and accurately.

\section{ION IMPLANTATION EFFECTS ON FOLLOWING PARAMETERS AS SEEN FROM MICRO STRUCTURAL ANALYSIS}

\subsection{Ion Mass}

Given the current understanding of ion-beam-induced disordering processes in mature Semiconductor materials such as $\mathrm{Si}$ and GaAs, one can select two limiting cases based on the Characteristics of the collision generally generated by energetic ions penetrating through a crystal. Cases of bombardment depend with light and heavy ions relative to the masses of the host atoms of the material under bombardment. In the case of light ions, collision cascades (mass of something that falls) are very dilute and consist mostly of simple point defects such as vacancies and interstitials position defects. But In the case of heavy ions, where the nuclear energy loss rate is large. Bombardment by intermediate mass ions represents a combination of these two limiting cases. A detailed study of damage build-up in $\mathrm{GaN}$ under light (12C) and heavy (197Au) ion bombardment was recently reported. The following similarities between these two irradiation regimes have been pointed out [33]. Important dynamic annealing of ion-produced defects has been observed for both regimes (an ordered way of doing something) at LN2 and RT. For both irradiation regimes, the damage depth profile, as measured by RBS/C, has two peaks $Đ$ the surface and bulk defect peaks. This feature are responsible to high defect mobility and high efficiency of the GaN surface for trapping of migrating point defects from normal to interstitial points. Similarly the damage build-up behavior at LN2 has been observed for both light and heavy ion Bombardment. However, the following differences between light and heavy ion bombardment regimes have also been make clear to observed [34].Completely different damage accumulation behavior has been observed for RT bombardment by light (12C) and heavy (197Au) ions). No damage saturation in the GaN bulk during irradiation with light ions has been observed, as measured by RBS/C. This fact may be explained by the difference in the defects formed during bombardment with light and heavy ions (for example, different size of planar defects). However, the chemical effects of implanted carbon and/ or gold atoms may also influence the build-up of radiation damage in GaN, and this requires additional study. A comparison of the disorder levels, as measured by RBS/C, with the results of TRIM that the defect annihilation efficiency is higher for light-ion Bombardment than that for irradiation with heavy ions bombardment. This result is consistent with the fact that the defect generation rate is larger in the case of heavy-ion bombardment. Such an increase in the generation rate of defects enhances the rate of interaction between mobile defects, and, consequently, promotes the formation of defect complexes rather than defect annihilation via Dynamic annealing.[35] Different dependencies of the magnitude of the surface defect peak on beam flux have been observed for light and heavy ions.

\subsection{Ion Energy}

The effect of ion energy on implantation disorder in GaN has illustrates that the main features of damage build-up do not change upon increasing the energy of Au ions from 100 to $2000 \mathrm{keV}$.for that energy it is stable. One can see the same highly effected damage build-up and the nucleation of two amorphous layers (surface and buried) for all three ion energies. In all three cases, the two amorphous layers $Đ$ at the surface and in the bulk $Đ$ nucleate and grow via a layer-by-layer by amorphization process with increasing ion dose,. Ultimately, with further increasing ion dose, these two layers meet, resulting in a thick surface layer of amorphous material. [36]

\subsection{Implantation Temperature}

One way to avoid high levels of undesirable ion beam damage is elevated temperature implantation. This fact may explain why the effect of substrate temperature on implantation disorder in GaN bombarded with 40 and $300 \mathrm{keV}$ $\mathrm{Au}$ ions increase in implantation temperature from LN2 to RT not only reduces implantation damage but also dramatically changes the damage build-up behavior. Indeed, not the damage saturation in the bulk has been observed in the case of implantation with $300 \mathrm{keV}$ Au ions at LN2 with increasing ion dose, amorphization proceeds layer-by-layer from the GaN surface[37], and, for a dose of $2.5 \times 10^{15} \mathrm{~cm}$ of $300 \mathrm{keV}$ Au ions, the whole implanted region is rendered amorphous. In the case of elevated temperature ion bombardment of $\mathrm{GaN}$, amorphization is not observed, but the behavior is more complex due to very efficient ion-beam-induced erosion of the GaN surface for high ion doses [38] for elevated temperature bombardment, apparent strong surface disordering, as monitored by RBS/C, can occur but is a result of $\mathrm{C}$ contamination of the $\mathrm{GaN}$ surface during ion bombardment. Special precautions should be made to suppress such $\mathrm{C}$ contamination during high-dose ion bombardment at elevated temperatures an increase in implantation temperature leads to an increase in the rate of all thermally activated point defect processes (defect diffusion, direct and indirect annihilation, formation of complexes, trapping

$$
\begin{aligned}
& \text { www.ijtrs.com } \\
& \text { www.ijtrs.org }
\end{aligned}
$$




\section{J $\mathbb{R} \leqq$ International Journal of Technical Research \& Science}

of free defects by defect complexes and impurities, etc.). The nature of 'stable' defect complexes formed at RT or elevated temperatures during dynamic annealing may, as a consequence, result in a higher level of residual disorder.

\subsection{Beam Flux}

The effect of beam flux on lattice disorder in GaN has observed. RBS/C spectra illustrating the effect of beam flux on implantation damage produced by $300 \mathrm{keV}$ Au ion bombardment of GaN at LN2. It is seen that, with increasing beam flux, the magnitude of the bulk defect peak also increases for both LN2 and RT implantation regimes. This normal flux effect is consistent with the current understanding of ion beam damage build-up in semiconductors under implantation conditions when substantial dynamic annealing of radiation defects takes place an increase in beam flux decreases the average time interval between collision cascades which spatially overlap. Such an increase in the generation rate of point defects with increasing beam flux enhances the rate of interactions between mobile defects and, therefore, enhances the formation of defect complexes [39].

\subsection{Ion-Beam-Induced Porosity}

AFM and XTEM results had shown that high-dose ion bombardment of epitaxial GaN films with heavy ions results in anomalous swelling of the implanted region.

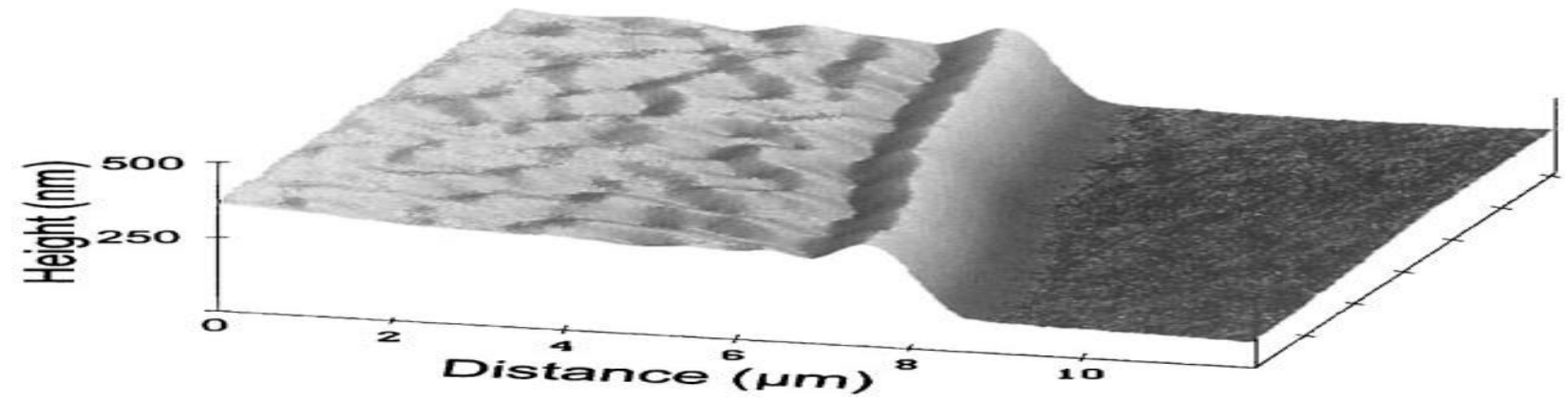

Fig.4.1 A Tapping Mode AFM Image Illustrating the Border Between Implanted (on the left) and Unimplanted (on the right) Areas of a GaN Sample Bombarded with $2 \mathrm{MeV}$ Au Ions at LN2 to a Dose of $1 \times 10^{16}$ cm with a Beam Flux of $5 \times 10^{12} \mathrm{~cm}$

An AFM image in Fig. 5 illustrates the border between implanted (on the left) and unimplanted (on the right) areas of a GaN sample bombarded with $2 \mathrm{MeV}$ Au ions at LN2 to a dose of $1 \times 10^{16} \mathrm{~cm}$. As clearly seen, ion implantation has caused pronounced material swelling with a step height as large as _1700 A $\hat{\mathrm{E}}$. In addition, the implanted area exhibits large-scale roughness [40]

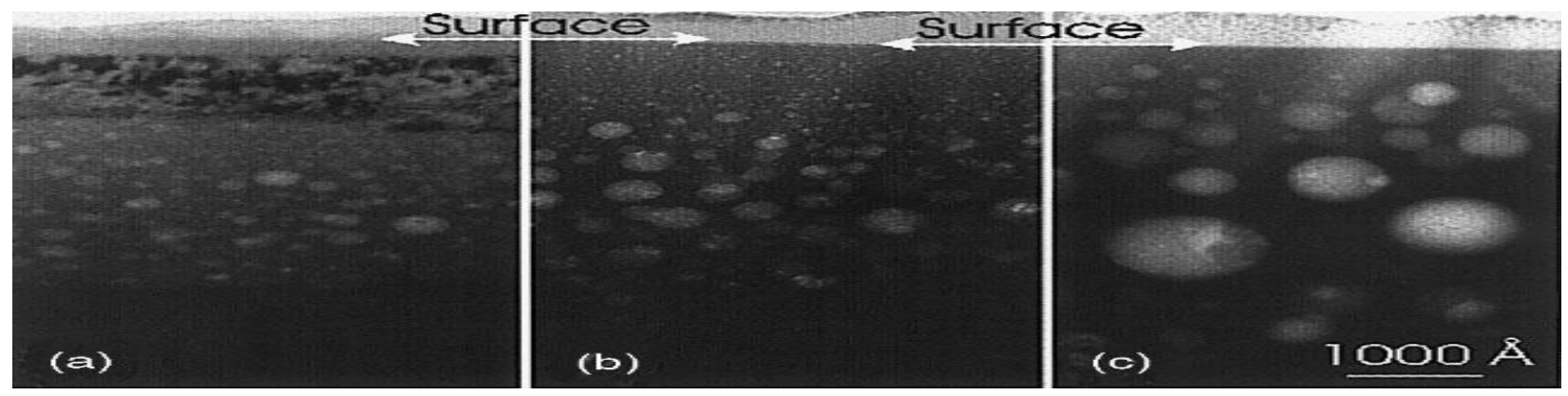

Fig.4.2 Bright-Field XTEM Images of GaN Bombarded with $2 \mathrm{MeV}$ Au Ions at LN2 with a Beam Flux of 5 $\times 10^{12} \mathrm{~cm}$ to Doses of $5 \times 10^{15} \mathrm{~cm}(\mathrm{a}), 1 \times 10^{16} \mathrm{~cm}(\mathrm{~b})$, and $3 \times 10^{16} \mathrm{~cm}$ (c). All Three Images are of the Same Magnification

In Fig. 4.2 bright-field XTEM images of GaN bombarded with $2 \mathrm{MeV}$ Au ions at LN2 to three Different doses are shown. Note that all three images were taken with the same magnification. The XTEM image from Fig. 4.2(a) (a dose of $5 \times 10^{15} \mathrm{~cm}$ ) clearly shows two amorphous layers $Ð$ surface and buried $Đ$ separated by a layer of heavily damaged but still crystalline material. The images from Fig. 4.2(b) and (c), which are for higher ion doses (doses of $1 \times 10^{16}$ and $3 \times 10^{16} \mathrm{~cm}$, respectively), reveal that ion bombardment to these doses results in the formation of amorphous layers continuous to the surface Fig. 4.2 clearly illustrates that GaN amorphized by heavy-ion bombardment is porous. The amorphous layers have voids or gas bubbles, which are close-to-spherical in shape. The average radius of the voids/bubbles increases according to the nuclear energy loss profile of Au ions. A comparison of Fig. 4.2(a) \pm (c) indicates that, with increasing ion dose, the size of the voids/bubbles also increases. Fig. 14 also 


\section{J $\mathbb{R} S$ International Journal of Technical Research \& Science}

suggests that small voids/bubbles agglomerate into larger ones with increasing ion dose. With increasing ion dose, implantation also causes large-scale surface roughness, which occurs only when buried and surface amorphous layers meet .It should be noted that similar porous structures have also been observed in GaN films amorphized by $300 \mathrm{keV} \mathrm{Au}$ ion bombardment [41]. However, in this latter case of keV heavy-ion bombardment, the ion penetration depth is significantly smaller than that in the case of $\mathrm{MeV}$ ion irradiation, which makes the material swelling less pronounced. The effects of ion-beam-induced porosity and concomitant material expansion reported, in fact, not new. Similar effects have been observed in some other semiconductors. In the case of GaN, ion-beam-induced porosity has been attributed to material decomposition with the formation of $\mathrm{N} 2$ gas bubbles in a Ga-rich matrix during heavy-ion bombardment.

\subsection{Mechanical Properties}

There has been considerable interest in determining the mechanical properties of GaN. Indeed, studies of the processes controlling contact damage, wear, and cracking of GaN layers have significant technological importance. Moreover, understanding the deformation behavior of ion-beam-modified $\mathrm{GaN}$ is not only important for contact damage issues in the GaN industry but is also necessary for understanding the evolution of the structural characteristics of $\mathrm{GaN}$ under ion bombardment. The mechanical properties of semiconductors are usually studied (i) by conventional Vickers micro-hardness testing, or (ii) by continuous-depth-sensing indentation testing (generally known as nanoindentation), which is a much more powerful technique. Indeed, nanoindentation is capable of providing information on a range of mechanical properties such as hardness and elastic properties and their variation continuously with indenter penetration depth. Such information can be readily obtained directly from force displacement measurement. In addition, nanoindentation is ideal for measuring the mechanical properties of very thin films. It is well-known that, if the substrate is harder than the film, the substrate influence is usually negligible when the penetration depth of the indenter is less than_10\% of the film thickness [42].
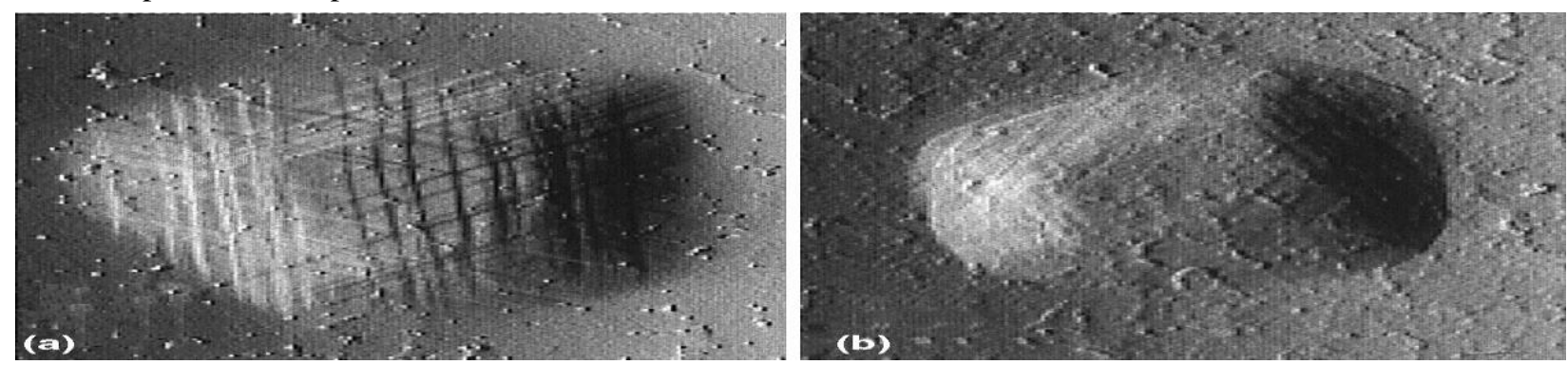

Fig.4.3. Typical Amplitude-mode AFM Images of (a) as-grown and (b) 'Ion-damaged' GaN Films Indented at a Maximum Load of $100 \mathrm{mN}$ (Horizontal Field Width is $4 \mathbf{~ m m}$ for Both Images (a) and (b)

These AFM images clearly illustrate that slip, which occurs during loading of as-grown GaN, is strongly suppressed in 'ion damaged' GaN.

\subsection{Annealing of Implantation Damage}

In the semiconductor industry, ion implantation used for electrical and optical doping is always followed by an annealing step. Such annealing is necessary (i) to remove implantation-produced lattice disorder and (ii) to electrically/optically activate implanted species by stimulating their migration into energetically favorable lattice sites. Post-implantation annealing is a very important technological step since device performance is highly dependent on the efficiency of such annealing. [43]

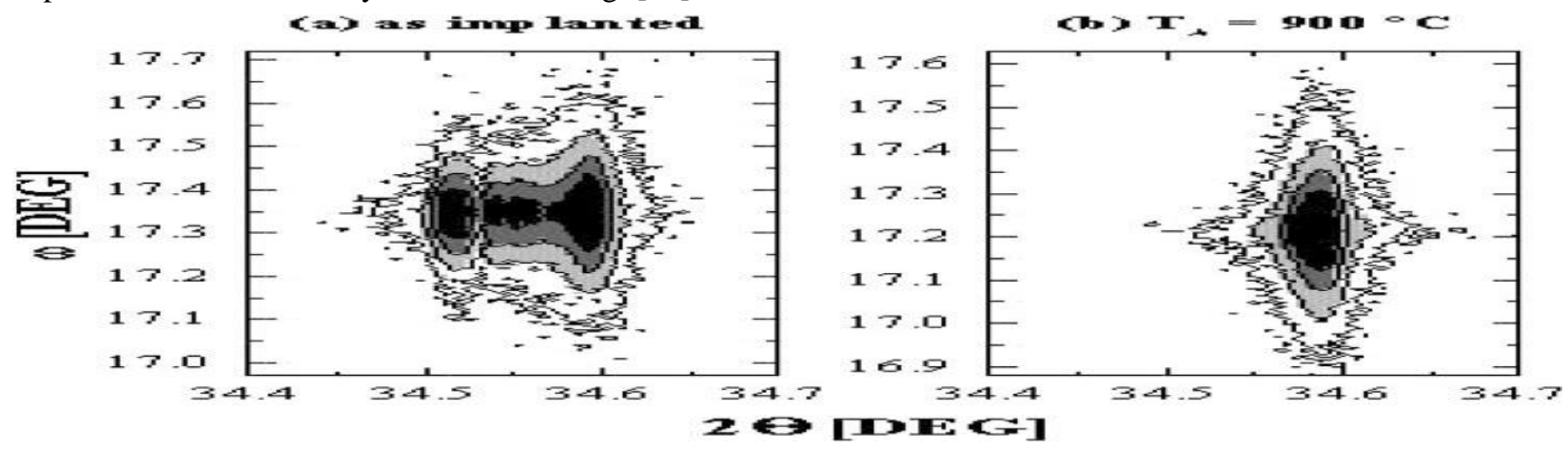

Fig. 4.4 XRD 2-axis _-2_ map of the (0002) GaN Peak (a) Directly After Be Implantation With a Dose of $2.5 \_10 \mathrm{~cm}$ and after Subsequent Annealing to a Temperature of $900^{\circ} \mathrm{C}(\mathrm{b})$ for $10 \mathrm{~min}$

DOI Number: https://doi.org/10.30780/IJTRS.V05.I03.003

pg. 23

www.ijtrs.com

www.ijtrs.org

Paper Id: IJTRS-V5-I1-004

Volume V Issue III, March 2020 


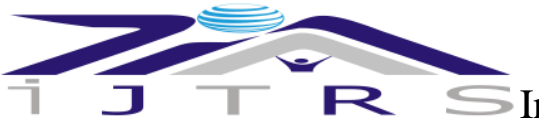

International Journal of Technical Research \& Science

Fast, homogenous on large wafers, reproducible result. Exact control of implanted amount of dopant (measurement of current), especially important for small dopant level, Excellent cleaning of dopants during implantation by mass separation, Simple mask techniques with thick oxide-, nitride-und photo lacquer layers, Doping through thin passivation layers and Doping profile easily adjustable by multiple implantations (not possible by diffusion techniques. Very small amount of devices structures possible through this kind of technique. Here we have discussed applications which resultants from the ion implantation in to $\mathrm{GaN}$ material. Due to the ion implantation we have get different chemical and technically implicational changes which were not seen before that ion implantation process. Here we had used many techniques and tolls and practices it with variety of applications which leads to the formation of stable materials, gasses and complex nature opponents which then find useful in industrial growth of materials and facilitating of fulfilling necessities for bio, physical and chemical experiments and emerging its relations with other fields and to investigate about its arising and developments. As with other semiconductor material Systems, ion implantation is expected to play an Enabling role for advanced device fabrication in the III-Nitride material system. As reported here, ion Implantation has already been used to achieve $\mathrm{n}$ type and P-type doping of GaN and to fabricate the first GaN JFET. As further understanding is obtained on implantation induced defects, activation Annealing and the role of other impurities in these Materials, it is anticipated that ion implantation will be more widely used for III-Nitride devices [44]. Moreover, since ion implantation has been the foundation of most advanced electronic and, to a lesser extent, photonic devices in mature semiconductor materials systems such as silicon and Gallium Arsenide [45]. It is important to determine the applicability of ion implantation to III-N based devices. In particular the demonstration of selective area implants isolation and doping will allow new III-N based device structures such as lasers and FETs with selectively doped contact Regions, planar waveguides created by implant isolation, and implantation tailored current guiding in LEDs and lasers. We have studied the micro-structural Properties of Ne implanted GaN in the background Framework of Nanocavities formation which is resultants from ion implantation. The neon ions form gas vacancy Clusters when gas Atoms desorbs on high temperature thermal annealing which Transform into empty cavities. The lowest implantation dose of $10^{14} \mathrm{~cm}^{-2}$ has shown no drastic changes, the spectra are nearly similar to that of as-grown sample because for the production of stable cavities this dose of implanted ions appears insufficient. Next, which Grow with increase in concentration of implanted ions is the higher doses produce nucleation for stable cavities. A New feature observed at $1595 \mathrm{~cm}^{-1}$ in Raman spectrum is suggested to be the vibration mode of cavities which is great achievement in specifying cavities vibrational frequency and intensity [46]. By ion implantation Defects produced are quite stable and cannot be completely removed by the Following high temperature annealing which is showing the stability of materials forming due to ion implantation process. One way to facilitate the annealing process is to reduce the Concentration of residual damages (after implantation) by performing the ion implantation at elevated temperatures because that temperature is very useful for operation. In the temperature range from room temperature (RT) to $1000^{\circ} \mathrm{C}$ our recent studies have shown that lattice disorder in $\mathrm{GaN}$ bombarded with Ar+ ions demonstrated a Characteristic retrograde behavior (2). The amount of Disorder decreased with increasing of implantation Temperature up to $500^{\circ} \mathrm{C}$. The irradiation at higher Temperatures resulted in an increase of the disorder, which Reached maximum at about $700^{\circ} \mathrm{C}$ and decreased again with further increase of the temperature so by ion implantation we can decrease disorders in materials and can study their characteristics behaviors and shows the variation in defects with implantation which is basically the importance of ion implantation [47].

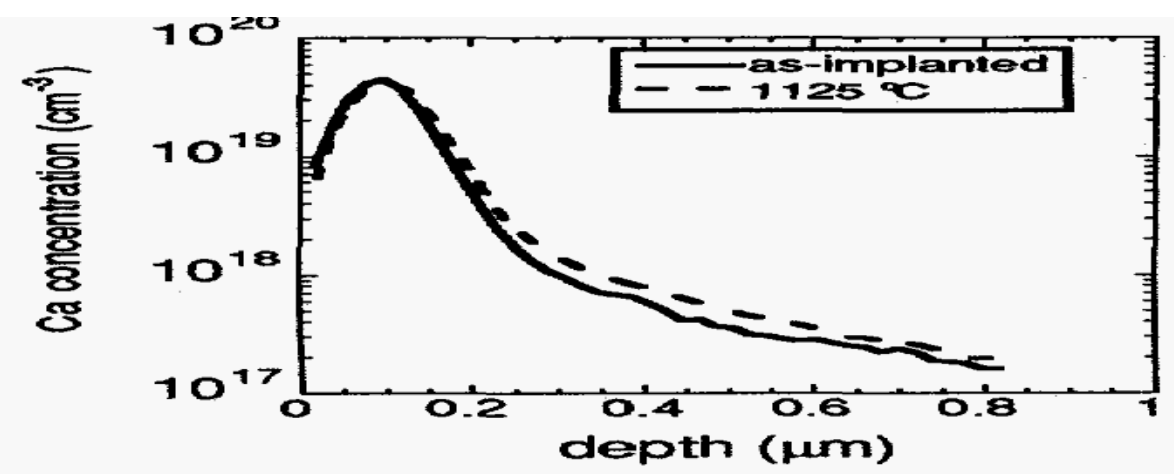

Fig. 4.5 Depth Vs Ca-Concentration per $\mathrm{cm}^{3}$ at $1125^{\circ} \mathrm{C}$

Finally as shown by Fig.4.5, above implanted $\mathrm{Ca}$ also shows no measurable redistribution even at $1125^{\circ} \mathrm{C}$ which is also important for experts. . The lack of significant redistribution of all the donor species and acceptor studied suggests that ion Implantation will be a viable and stable the JFET demonstrates good modulation characteristics with nearly complete pinch-off at a threshold voltage. These devices had a unity current gain cutoff frequency (ft) of 


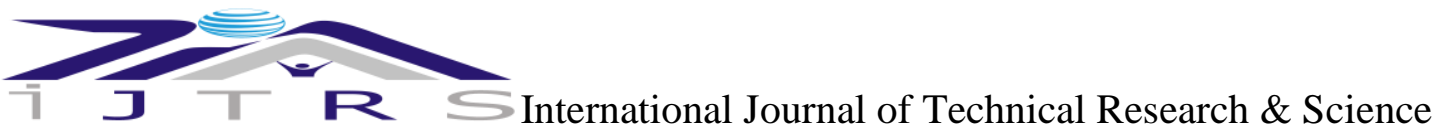

2.7 GHz and a maximum oscillation frequency (max) of $9.4 \mathrm{GHz}$ These frequency matches are in the range reported for epitaxial GaN MES present results for the successful n- and p-type implant doping of GaN that lead to the first GaN junction field effect transistor (JFET). The JFET was produced with all ion implantation doping.FETs. Ion implantation was found used to determine the ionization energy of $\mathrm{Ca}$ in $\mathrm{GaN}$ [48]. When applying ion implantation doping to device structures it is important to know how the impurities redistribute during the activation anneal. Initial studies on the redistribution of implanted impurities in $\mathbf{G a N}$ were limited to temperatures up to -800 ${ }^{0} \mathrm{C}$ [49]. However, when it became apparent that temperatures on-the-order-of $1100{ }^{\circ} \mathrm{C}$ are required to achieve activated dopants the technology for controllable doping of GaN. Furthermore, due to the lack of diffusion, external source diffusion appears not to be practical in IV. GaN JFET As discussed earlier, ion implantation doping and isolation has played a critical role in The realization of many high performance devices in most mature semiconductor materials systems such as $\mathrm{Si}$ and GaAs. This is also expected to be the case for III-N based devices as the quality of the III-N materials continues to improve, even Though the III-N materials are far from mature, all ion implanted transistors have already been demonstrated [50]. Our study shows that the annealing-induced defect formation in as-grown GaN dominated over the doping effect by ion implantation. This defect is hypothesized to be-of a vacancy or a depassivated impurity nature. To range from 1.4 to $3.6 \mathrm{eV}$ the formation energies for this defect are estimated. But still the physical origin of this defect is unknown. In the case of Mo_implanted GaN film. Free-carrier concentration could be suppressed by three orders of magnitude with ion implantation up to $690{ }^{0} \mathrm{C}$. The correlation between improved optical and electrical properties and the annealing-induced defects was observed which was not seen before implantation process, Ion implantation may be the most effective post-growth doping method, and however, for implantation to become practical, a broad range of implantation parameters must be explored and controllable annealing techniques must be developed in N-type GaN.

\subsection{METAL ORGANIC VAPOR DEPOSITION (MOCVD):}

The first process for realization of any semiconductor device is to grow the crystal with different layers of materials and different doping concentration and that concentration layer give the relative information about crystal symmetry and orientation .for that purpose we are using some important and flexible techniques which is being used for crystal growth since 1960 , as Metal Organic Chemical Vapor Deposition (MOCVD) technique which is also called OMCVD (Organic metallic Chemical Vapor Deposition) or MOVPE (Metal Organic vapor phase epitoxy), and that techniques are used for uniform growth and deposition of wafer on substrate molecule . Before MOCVD technique, VPE (Vapor Phase Epitoxy) and LPE (Liquid Phase Epitoxy) were used for the growth of layered devices. MOCVD uses MO (Metal organic) compound as source of the material [51]. For the growth of GaN and related materials MOCVD is the workhorse. In 1971 Manasevit et al applied this technique for the deposition of GaN AlN [52]. For depositing thin layers of atoms onto a semiconductor wafer MOCVD technique is used. To create a material which has specific optical and electrical properties we can build up many layers by using MOCVD technique, each one of a precisely controlled thickness. By depositing atoms on a wafer substrate MOCVD is a widely used method for Preparing epitaxial growth Structures .The principle of MOCVD is that the atoms are deposited by decomposing organic molecules (precursors) while they are passing over the hot substrate and then layers starts thinning from thicker [53] the properties of the crystal can be changed on atomic scale By varying the composition Of the gas. The undesired remnants and constituents are removed or deposited on the side walls of the reactor, as then used by edge bead removal process III-V semiconductors of high structural order and purity are prepared through MOCVD technique [54]. The basic principles of MOCVD growth are elaborated below.

Typical MOCVD consist of four parts.

$>$ Gas handling system

$>$ Reactor chamber

$>$ Heating system for paralysis temperature

$>$ exhaust system and safety apparatus

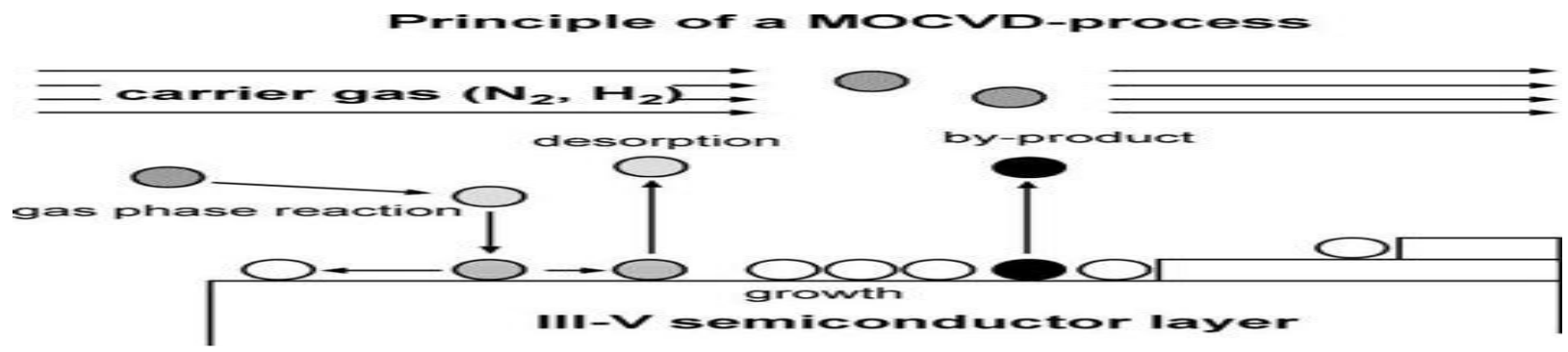

Fig. 4.6 Principle of a MOCVD Process [4]

DOI Number: https://doi.org/10.30780/IJTRS.V05.I03.003

pg. 25

WWW.ijtrs.com

WWW.ijtrs.org

Paper Id: IJTRS-V5-I1-004

Volume V Issue III, March 2020 

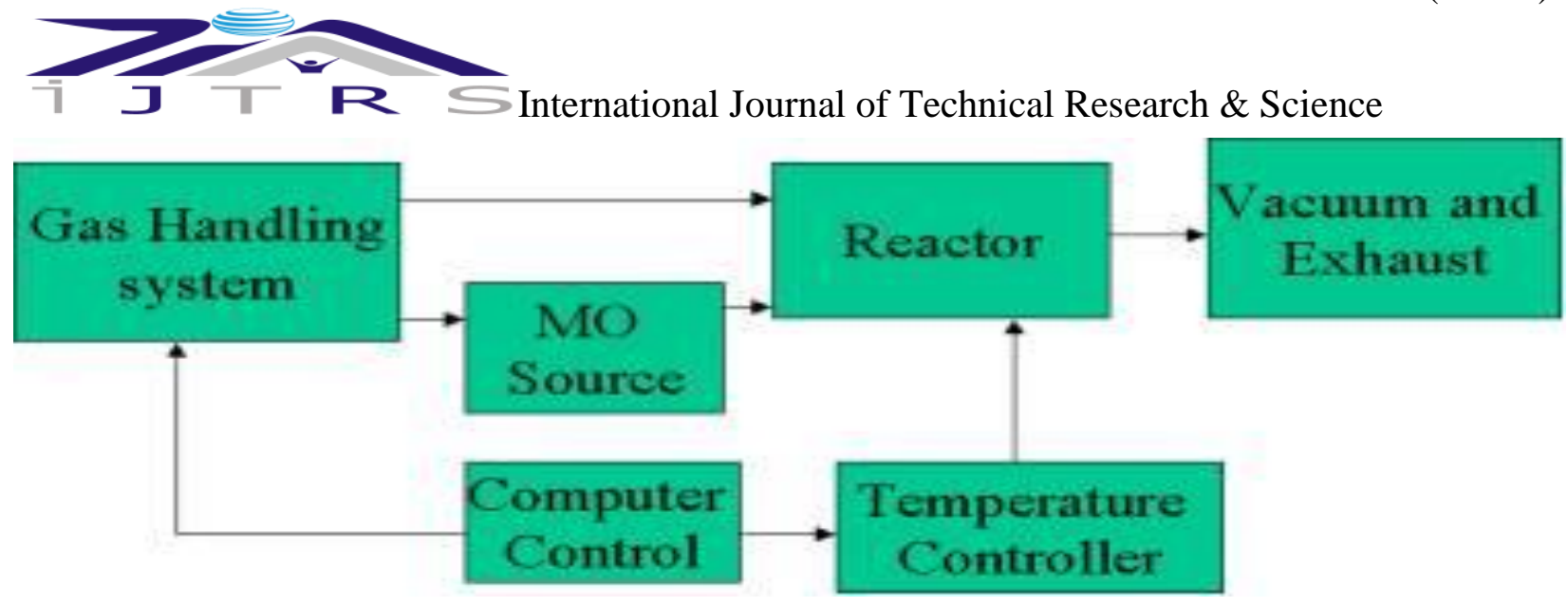

Fig. 4.7 Basic Structure of the System

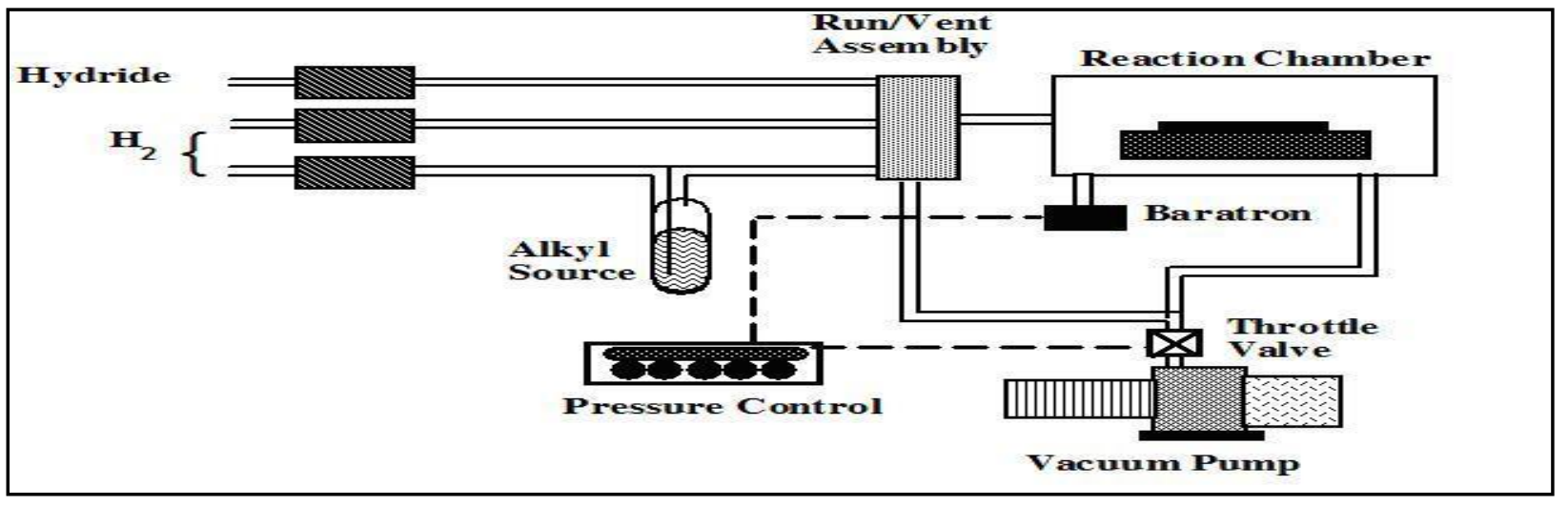

Fig. 4.8 Schematic Representation of MOCVD Reactor

The above all process gives unique and precise results because the whole system is in a computer controlled chamber and there is no choice for error to fluctuate. Sources of alkyls and hydrides acts as gas handling system, and all of the valves, pumps and instruments necessary to the gas flows and mixtures. For uniform and epitaxial grown In order to grow high quality layers the gas handling system has to be clean and leak tight clean is useful to carry out all dust particles from the wafer surface to transport alkyls from the source to the reactor chamber Stainless steel tubes are used and electronic mass flow controllers and to the reactor chamber a thermal bath system is used to deliver precisely controlled amounts of gases Different amount of gases are used in gas handling system. For pneumatic valves $\mathrm{N}_{2}$ (ordinary) gas is used. As a carrier of metal organic (MO) source Hydrogen gas is used. to dope as n-type $\mathrm{SiH} 4$ is used. As a reacting gas Ammonia is used. All these gases are controlled by mass flow controller and pneumatic valves and [55]. MOCVD growth takes place in a reactor shown in figure. It is a chamber made of a material that does not react with the chemicals being used. It must also needed and usually withstand high temperatures. This chamber is composed of reactor walls, gas injection units and temperature control units. Liner, a subsector usually the reactor walls that are made from quartz or stainless steel. Cooling water must be flowing through the channels within the reactor walls to prevent overheating. In the reactor chamber between the reactor wall and the subsector Special glasses, such as ceramic or quartz are often used as the liner. at controlled temperature in a reaction chamber A substrate is mounted on a subsector. The subsector is made from a material resistant to the metal organic compounds used; graphite is sometimes used. For growing nitrides and related materials, to prevent corrosion by ammonia $\left(\mathrm{NH}_{3}\right)$ gas a special coating on the graphite subsector is necessary. Through the run assembly unit the hydrides such as $\mathrm{NH}_{3}$ and $\mathrm{SiH}_{4}$ for nitrides Materials enter the reaction chamber while the carrier gas is introduced via devices known as 'bubblers'. Through the metal organic liquid in the alkyl source the carrier gas is bubbled, which picks up some of metal-organic-vapor and then transports it to the reactor chamber. During the reaction are deposited on substrate Chemical reaction takes place in the reaction chamber and the atoms of the required semi-conducting film formed. The amount of metal organic vapor transported depends on the bubbler temperature and rate of carrier gas flow. By Pressure Maintenance System for the growth of high quality crystal a suitable constant pressure is maintained [56]. There are some metal organic (MO) compounds, which are typically metal atoms with a number of alkyl radicals attached, with ethyl isopropyl, methyl are being the most common for the growth of compound semiconductors. Some of the widely used MO compounds are given below. 


\section{I}

Trimethylgallium, triethylgallium, trimethylindium, trimethylaluminium. Trimethylgallium Ga $\left(\mathrm{CH}_{3}\right)_{3} \mathrm{TMGa}_{\mathrm{react}}$ with $\mathrm{NH}_{3}$ at a substrate which is heated to roughly $1000^{\circ} \mathrm{C}$.

The reaction is given below:

$\mathrm{Ga}\left(\mathrm{CH}_{3}\right)_{3}+\mathrm{NH}_{3} \longrightarrow \mathrm{GaN}+3 \mathrm{CH}_{4}$

Through control unite the pressure can be changed. During the reaction Toxic waste products formed are converted to solid or liquid wastes for recycling (preferably) or disposal [57]

\section{CONCLUSION}

The GaN structure as reported previously is realized here to be most stable by considering crystal offsets and heterojunctions maps. The GaN p-type material is shown by considering low temperature growth on buffer thin film.The GaN application is shown important in case of MOCVD doping actually epitaxial and stable.The band structure of $\mathrm{GaN}$ is shown by considering spin orbital interaction influences for mixing energies. The lattice parameters of the wurtzite $\mathrm{GaN}$ at $300 \mathrm{~K}$ is given in case of MOCVD doping.Ion implantation is shown a highly developed tool for modifying the properties and structure of semiconductors materials Ion implantation is used in semiconductor device fabrication and various applications in materials science research and in metal finishing. In the target the ions introduce both the chemical change that they can be a different element than the target, and a structural change in target and that the crystal structure of the target can be damaged or even destroyed and vanished.ion implantation structure and procedure is shown.Ion implantation changes and damages are shown in detail here in this paper in case of lattice disorder, dislocations, imperfections, damages.Microstructure analysis as a result of ion implantation is shown.

Surface and bulk defect peaks are mostly responsible to high defect mobility and high efficiency of the GaN surface for trapping of migrating point defects from normal to interstitial points. Different dependencies of the magnitude of the surface defect peak on beam flux have been observed for light and heavy ions. The two amorphous layers $Đ$ at the surface and in the bulk $Đ$ nucleate and grow via a layer-by-layer by amorphization process with increasing ion dose,. Ultimately, with further increasing ion dose, these two layers meet, resulting in a thick surface layer of amorphous material.Implantation temperature from LN2 to RT not only reduces implantation damage but also dramatically changes the damage build-up behavior. The nature of 'stable' defect complexes formed at RT or elevated temperatures during dynamic annealing may, as a consequence, result in a higher level of residual disorder. Normal flux effect is consistent with the current understanding of ion beam damage build-up in semiconductors under implantation conditions when substantial dynamic annealing of radiation defects takes place an increase in beam flux decreases the average time interval between collision cascades which spatially overlap. AFM and XTEM results had shown that high-dose ion bombardment of epitaxial GaN films with heavy ions results in anomalous swelling of the implanted region. it is illustrated that GaN amorphized by heavy-ion bombardment is porous. The amorphous layers have voids or gas bubbles, which are close-to-spherical in shape, also suggests that small voids/bubbles agglomerate into larger ones with increasing ion dose. With increasing ion dose, implantation also causes large-scale surface roughness, which occurs only when buried and surface amorphous layers meet in the case of $\mathrm{GaN}$, ion-beam-induced porosity has been attributed to material decomposition with the formation of $\mathrm{N} 2$ gas bubbles in a Ga-rich matrix during heavy-ion bombardment. There has been considerable interest in determining the mechanical properties of GaN. Indeed, studies of the processes controlling contact damage, wear, and cracking of GaN layers have significant technological importance. Moreover, understanding the deformation behavior of ionbeam-modified GaN is not only important for contact damage issues in the GaN industry but is also necessary for understanding the evolution of the structural characteristics of GaN under ion bombardment, These AFM images clearly illustrate that slip, which occurs during loading of as-grown GaN, is strongly suppressed in 'ion damaged' GaN .Post-implantation annealing is a very important technological step since device performance is highly dependent on the efficiency of such annealing, and advantages are shown.

Here we had used many techniques and tolls and practices it with variety of applications which leads to the formation of stable materials, gasses and complex nature opponents which then find useful in industrial growth of materials and facilitating of fulfilling necessities for bio, physical and chemical experiments and emerging its relations with other fields and to investigate about its arising and developments. As with other semiconductor material Systems, ion implantation is expected to play an Enabling role for advanced device fabrication in the IIINitride material system. As reported here, ion Implantation has already been used to achieve n-type and P-type doping of $\mathrm{GaN}$ and to fabricate the first GaN JFET By ion implantation Defects produced are quite stable and cannot be completely removed by the Following high temperature annealing which is showing the stability of materials forming due to ion implantation process . Implanted $\mathrm{Ca}$ also shows no measurable redistribution even at $1125{ }^{\circ} \mathbf{C}$ which is also important for experts, our study shows that the annealing-induced defect formation in as-grown GaN dominated over the doping effect by ion implantation. This defect is hypothesized to be-of a vacancy or a 


\section{J}

depassivated impurity nature, Semiconductors of high structural order and purity are prepared through MOCVD technique, and MOCVD structure is shown.

\section{REFERNCES}

[1] MN d'Eurydice et al, Micro-electron Journal, 36, 1029 (2005).

[2] Zhe Chuan Feng, Kun Li, Yun Tian Hou, Jie Zhao, W. Lu and W. E. Collins, 200, 3224 (2006).

[3] Rong-piang Wang, Hachizo Muto and Takeshi kusumon, Optical materials. 23, 15 (2003).

[4] Takahiro Kawashima, Hisashi Yoshikawa, Sadao Adachia, Shunro Fluke and Kohji Ohtsuka, J. Appl. Phys. 82, 3528 (1997).

[5] B. Shen, Y. G. Zhou, Z. Z. Chen, P. Chen, R. Zhang, Y. Shi, Y. D. Zheng, W. Tong and W. Park, Appl. Phys. A. 68, 593 (1999).

[6] Hiroshi Amano, Masahiro Kito, Kazumasa Hiramatsu and Isamu Akasaki, Jpn. J. Appl. Phys. 28, L2112 (1989).

[7] Goldberger et al, Nature 422, 599 (2003).

[8] J.I Pankove \& T.D Moustakas, Gallium Nitride (GaN) I. San Deigo. Academic press (1998).

[9] O. Ambacher, J. Phys. D 31, 2653 (1998).

[10] Bougrov V, Levinshtein M.E, Rumyantsev S.L and Zubrilov A. Properties of advanced semiconductor Materials GaN, AlN, InN, SiC, SiGe. John Wiley \& Sons, Inc, Newyork, 1 (2001).

[11] H. Amano, M. Kito, K. Hiramatsu and I. Akasaki: Jpn. J. Appl. Phys. 28, L-2112 (1998).

[12] S. Nakamura, T. Mukai and M. Senoh: Jpn. J. Appl. Phys. 30, L1998 (1991).

[13] J. Q. Duan, B. R. Zhang, Y. X. Zhang, L. P. Wang, G. G. Qin, G.Y. Zhang, Y. Z. Tong, S. X. Jin, Z. J. Yang, X. Zhang and Z. H. Xu. J. Appl. Phys. 82, 5745 (1997).

[14] S. J. Pearton, C. R. Abernathy, R. G. Wilson, J. M. Zavada, C. Y. Song, M. G. Weinstein, M. Stavola, J. Han and R. J. Shul, Nuclear Instruments and Methods in Physics Research B, 147, 171 (1999).

[15] C. H. Seager, S. M. Myers, G. A. Petersen, J. Han, T. Headley. J. Appl. Phys.

[16] R. K. Roy and A. K. Pal. Materials Letters 59, 2204 (2005).

[17] Xu Jianyong Yang, Gail J. Brown, Mitra Dutta, Michael A and Stroscio. J. Appl. Phys. 98, 043517-1 (2005).

[18] W. You, X. D. Zhang, L. M. Zhang, Z. Yang, H. Bian, Q. Ge, W. X. Wang and Z.M. Liu. Physica B. (2007).

[19] H. Amano, M. Kito, K. Hiramatsu and I. Akasaki: Jpn. J. Appl. Phys. 28, L-2112 (1998).

[20] Ambacher, J. Phys. D 31, 2653 (1998).

[21] A. Majid, A. Ali, J. J. Zhu, W. Liu, G. J. Lu, W. B. Liu, L. Q. Zhang, Z. S. Liu, H. Wang, D. G. Zhao, S. M. Zhang, D. S. Jiang, Y. T. Wang, H. Yang and M. Israr. Phys. Scr. 77, 035601 (2008).

[22] A. Majid, Akbar Ali, J. J. Zhu, Y. T. Wang, W. Liu, G. J. Lu, W. B. Liu, L. Q. Zhang, Z. S. Liu, D. G. Zhao, S. M. Zhang, D. S. Jiang and H. Yang. J. Phys. D: Appl. Phys. 41, 025107 (2008).

[23] I. O. Usov a, N. R. Parikh a, D. Thomson b, Z. Reitmeier b, R. F Davis b a University of North Carolina at Chapel HillCurriculum in Applied and Materials Sciences Chapel Hill, NC, 27599-3287, USAb North Carolina State University Department of Materials Science and Engineering Raleigh, NC, 27695-7919, USA

[24] James W. Meyer, California institute of technology Ion implantation in semiconductors Pasadena, California 91109.

[25] http://www.p2pays.org/ref/38/37020.htm

[26] Omar Manasreh. III-Nitride Semiconductors: Electrical, Structural and Defects Properties. Published by, Elsevier (2000).

[27] Gerhard Spitzlsperger, Very brief introduction to ion implantation for semiconductor manufacturing, (2003).

[28] http://en.wikipedia.org/wiki/Ion_implantation

[29] S.O. Kucheyeva, ${ }^{*}$, J.S. Williamsa, S.J. Pearton Department of Electronic Materials Engineering, Research School of Physical Sciences and Engineering, The Australian National University, Canberra, ACT 0200, Australia department of Materials Science and Engineering, University of Florida, Gainesville, FL 32611, USA Accepted 18 January 2001.

[30] J.F. Gibbons, L.A. Christel, in: J.S. Williams, J.M. Poate (Eds.), Ion Implantation and Beam Processing, Academic Press, Sydney, 1984.

[31] W.-K. Chu, J.W. Mayer, M.-A. Nicolet, Backscattering Spectrometry, Academic Press, Orlando, 1978.

[32] H.H. Tan, J.S. Williams, J. Zou, D.J. Cockayne, S.J. Pearton, R.A. Stall, Appl. Phys. Lett. 69 (1996) 2364.

[33] H.H. Tan, J.S. Williams, J. Zou, D.J. Cockayne, S.J. Pearton, C. Yuan, Electrochem. Soc. Proc. 96-11 (1996)142.

[34] S.O. Kucheyev, J.S. Williams, C. Jagadish, G. Li, S.J. Pearton, Appl. Phys. Lett. 76 (2000) 3899.

[35] S.O. Kucheyev, J.S. Williams, C. Jagadish, J. Zou, M. Toth, M.R. Phillips, H.H. Tan, G. Li, S.J. Pearton, Mater.Res. Soc. Symp. Proc. 622 (2000) T7.9.1

[36] S.O. Kucheyev, J.S. Williams, C. Jagadish, J. Zou, G. Li, Phys. Rev. B 62 (2000) 7510.

DOI Number: https://doi.org/10.30780/IJTRS.V05.I03.003

pg. 28

www.ijtrs.com

Www.ijtrs.org 
[37] S.O. Kucheyev, J.S. Williams, C. Jagadish, J. Zou, V.S.J. Craig, G. Li, Appl. Phys. Lett. 77 (2000) 1455 S.O. Kucheyev, J.S. Williams, J. Zou, C. Jagadish, G. Li ,Appl. Phys. Lett. 77 (2000) 3577.

[38] C. Ronning, H. Hofsass, A. Stoetzler, M. Deicher, E.P. Carlson, P.J. Hartlieb, T. Gehrke, P. Rajagopal, R.F. Davis, Mater. Res. Soc. Symp. Proc. 595 (2000) W11.44.1.

[39] Ryssel/Ruge: „Ionenimplantation“, Teubner 1978 •H. Ryssel, H. Glawischnig „Ion Implantation Techniques“, Springer, Heidelberg 1982; ISBN: 3540118780.

[40] S.O. Kucheyev, J.S. Williams, C. Jagadish, J. Zou, G. Li, Phys. Rev. B 62 (2000) 7510.

[41] N. Parikh, A. Suvkhanov, M. Lioubtchenko, E. Carlson, M. Bremser, D. Bray, R. Davis, J. Hunn, Nucl. Instr. Meth. B 127/128 (1997) 463.

[42] C. Liu, B. Mensching, K. Volz, B. Rauschenbach, Appl. Phys. Lett. 71 (1997) 2313.

[43] S.O. Kucheyev, J.S. Williams, C. Jagadish, J. Zou, V.S.J. Craig, G. Li, Appl. Phys. Lett. 77 (2000) 1455 S.O. Kucheyev, J.S. Williams, J. Zou, C. Jagadish, G. Li

[44] A. Suvkhanov, J. Hunn, W. Wu, D. Thomson, K. Price, N. Parikh, E. Irene, R.F. Davis, L. Krasnobaev, Mater. Res.Soc. Symp. Proc. 512 (1998) 475.

[45] S.O. Kucheyev, J.S. Williams, C. Jagadish, J. Zou, V.S.J. Craig, G. Li, Appl. Phys. Lett. 77 (2000) 1455 S.O. Kucheyev, J.S. Williams, J. Zou, C. Jagadish, G. Li ,Appl. Phys. Lett. 77 (2000) 3577.

[46] Ryssel/Ruge: Ionenimplantation“, Teubner 1978 •H. Ryssel, H. Glawischnig „Ion Implantation Techniques“, Springer, Heidelberg 1982; ISBN: 3540118780.

[47] B.J. Pong, C.J. Pan, Y.C. Teng, G.C. Chi, W.-H. Li, K.C. Lee, C.-H. Lee, J. Appl. Phys. 83 (1998) 5992.

[48] A Majid1,2, A Ali2, J J Zhu1, W Liu1, G J Lu1,WB Liu1, L Q Zhang1, Z S Liu1, HWang1, D M Zhang1, TWang1, H Yang1 and M Israr2, Phys. Scr. 77 (2008) 035601 (4pp)

[49] J. Pearton: R. G. Wilson," and R. A. Stalld "Sandia National Laboratories, Albuquerque, NM, 87185-0603 bS. J. Pearton, UN. Of Florida, Gainesville, FL, 32611 "R. G. Wilson, Hughes Research Laboratories, Malibu, CA, 90265., Somerset, NJ, 08873

[50] W. You, X.D. Zhang, L.M. Zhang, Z. Yang, H. Bian, Q. Ge, W.X. Guo, W.X. Wang, Z.M. Liu_ School of Nuclear Science and Technology, Lanzhou University, Lanzhou 730000, People's Republic of China. Received 5 August 2007; accepted 19 January 2008.

[51] J. Xu, J. Li, R. Zhang *, X.Q. Xiu, D.Q. Lu, H.Q. Yu, S.L. Gu, B. Shen, Y. Shi, Y.D. Ye, Y.D. Zheng Laboratory of Solid State Microstructures, Department of Physics, Nanjing University, Nanjing 210093, China

[52] J. C. Zolper, a S. J. Pearton: R. G. Wilson," and R. A. Stalld "Sandia National Laboratories, Albuquerque, NM, 87185-0603 bS. J. Pearton, UN. Of Florida, Gainesville, FL, 32611 "R. G. Wilson, Hughes Research Laboratories, Malibu, CA, 90265 ., 08873.

[53] www.phys.ksu.edu/personal/mnakarmi/MOCVD/mocvd.html.

[54] H. M. Manasevit, F. M. Erdman, and W. I. Simpson, J. Electrochem. Soc, 118, 1864 (1971).

[55] http://www.anu.edu.au/CSEM/machines/MOCVD.html.

[56] Claudio R. Miskys, Michael K. Kelly, Oliver Ambacher, and Martin Stutzmann, phys. stat. sol. (c) 0, 1627 (2003).

[57] Hadis Morkc, Nitride Seomiconductor and Devices, Springer, 99 (1998). 